\title{
Hemangioma: caso clínico e revisão de literatura
}

\author{
Pantelis Varvaki Rados* \\ Joāo Jorge D. Barbachan* \\ Manoel Sant'Ana Filho** \\ Maurício Roth Volkweis***
}

\begin{abstract}
RESUMO
Os autores apresentam revisão de literatura e um caso clínico de hemangioma com características clínicas incomuns.
\end{abstract}

\section{SUMMARY}

The authors presente review of literature and a clinic report of a case of hemangioma with unusual characteristics.

\section{Introdução}

Os hemangiomas figuram entre as lesões mais freqüentes de cabeça $e$ pescoço, sendo a mais freqüente em crianças $(1,2,11,12)$. Talvez por se tratar de uma lesão que raramente trará algum prejuízo para o paciente, permaneça ainda pouco pesquisado, especialmente no que se refere a sua patogenia, embora bem descrito em todas as suas outras manifestações $(1,3,9,12)$.

Abordaremos então os diversos aspectos relacionados com o aparecimento e desenvolvimento da lesão, seus possiveis agentes etiológicos, sua patogenia e as diversas opções terapêuticas sugeridas. Por fim apresentaremos o caso clínico de uma lesão com algumas características diferentes da forma clássica de manifestaçāo do hemangioma, enfatizando a necessidade de uma conduta diagnóstica correta na busca da identificação precisa da doença.

\section{Revisão de Literatura}

Os hemangiomas figuram entre as lesōes tumorais mais freqüentes de cabeça e pescoço, sendo o tumor mais comum durante a infância $(1,2,11,12)$, estando geralmente presente ao nascimento $(3,4,5,7,9,11)$. Nos casos congênitos há involuçăo espontânea da lesão (1) e em quase todas as situações possui um cres- cimento auto-limitante $(4,5)$. Tem um comportamento neoplásico discutível (4), sendo que muitos autores $(1,5,9,10)$ preferem classificá-lo como um hamartoma.

As lesões possuem prognóstico excelente e segundo Shafer e colaboradores (9) não há recidiva nem malignidade, ressaltando que Bhaskar (3) e Thwaites (11) alertam para a possibilidade de malignidade em raros casos.

Há preferência de localização pela cavidade bucal e nasal, acima do trato respiratório na mucosa da orofaringe (2), especialmente nas mucosas labial, jugal, palato e língua $(1,7)$.

Os hemangiomas são mais freqüentes no sexo feminino $(1,5,9)$, mas Batsakis (2) e Bhaskar (3) afirmam não haver preferência por sexo. Também não há preferência por raça (2).

Microscopicamente as lesões se caracterizam por apresentar proliferação de células endoteliais, formando pequenos capilares $(1,3,9)$ constituídos por uma única camada de células, lembrando tecido de granulação jovem (9), ou então, capilares formando grandes espaços cavernosos $(1,3)$. Pode haver conjuntamente a proliferação de vasos linfáticos $(12,13)$. Apresentam pouco estroma (2) onde haverá possivelmente a presença de massas sólidas de célu- las endoteliais (1). São lesōes não encapsuladas (11).

As lesões bucais são planas $(1,3,9)$ ou elevadas $(3,9)$, de tamanhos e formas variáveis com coloração vermelho-azulado $(1,9)$ ou violácea $(12)$, sendo raramente bem delimitados (9). A lesão deve isquemiar quando pressionada $(3,5,11,13)$. À palpação geralmente săo de consistência mole $(3,5)$ podendo apresentar-se endurecidos quando em posição profunda $(2,3,5)$. Freitas (5) afirma que é possível a sensação de pulsação ao fluxo sangüíneo.

Ao exame radiográfico os hemangiomas de tecido mole năo possuem imagem (6) mas podem causar reabsorção do osso subjacente devido a pressão exercida pela lesão (5). Quando de localização intra-óssea o hemangioma tem imagem radiográfica dita em favos de mel, semelhante ao osteossarcoma (9), não possuindo limites definidos e podendo incluir no seu interior lesōes vasculares diversas (5), esse aspecto radiográfico pode ser confundido com o de outras lesões (12).

A etiologia dos hemangiomas per-

* Professor de Patologia da PUCRS e UFRGS

** Professor de Patologia da PUCRS e UFRGS, Professor do Mestrado em CTBMF da PUCRS

*** Aluno de Graduaçāo, Bolsista de Iniciaçāo Científica do CNPq

\section{R. Fac. Odontol.}

Porto Alegre
V. 33

N. 2 p.10-12 
manece controversa, parecendo ser de origem traumática (12), sendo resultado de uma resposta exagerada a traumas relativamente pequenos sofridos (2). De acordo com Freitas e colaboradores (5) as lesōes se originariam a partir de restos endoteliais congênitos. Segundo Thwaites (11) os mastócitos atuariam na patofisiologia do tumor, não apenas no seu aparecimento, mas também na perpetuação do processo, baseando-se no fato de que lesões em desenvolvimento apresentam um aumento do número de mastócitos na sua periferia e lesões em involução apresentam redução do número de mastócitos na sua periferia.

De acordo com a forma com que se manifesta clinicamente, podem ser classificados em capilares $(1,3,7,9,11,12)$, Cavernosos $(1,9,11,12)$, angioblástico (9), sistêmico difuso (9), metastizante (9), racemoso (9), nevo vinhoso (9) e juvenil $(3,11)$.

As opções terapêuticas são variadas: sutura parcial progressiva (12), embolização (11), compressão $(9,11)$, raio laser $(11)$, crioterapia $(1,9,11,12)$, neve carbônica $(1,9)$, soluçōes esclerosantes $(1,9,11,12)$, eletrocautério (3), cortico-esteróides (11) e excisão cirúrgica $(1,2,9,11,12)$. A escolha entre uma ou outra medida terapêutica depende de cada caso (1) e devem ser considerados a idade do paciente, a extensão, localizaçăo e tempo de evolução da lesảo $(2,10)$. Quando se opta por medidas cirúrgicas a punção e aspiração da lesão é indicada $(4,9)$ e a biópsia parcial deve ser evitada por causa do risco de hemorragias graves $(11,13)$.

Lesöes grandes podem interferir na fonação e mastigação do paciente (3) e estão sujeitas a sofrer traumatismos e infecção secundária $(1,5,9,11)$ devendo sempre o paciente ser alertado para essa possibilidade, evitando inclusive doenças dentárias (11), pois a manipulação de dentes relacionados a hemangiomas é extremamente delicada. Tumores com crescimento exagerado podem ter influências psicológicas sobre o paciente e o cuidado com esse aspecto pode ser tão im- portante quanto o tratamento médico empregado (11).

\section{Caso Clínico}

O paciente P.R.S.O., de 28 anos, sexo masculino, negro, pintor de automóveis, residente em Porto Alegre, procurou o serviço de Triagem da Faculdade de Odontologia da Universidade Federal do Rio Grande do Sul no intuito de realizar restauraçōes em dentes molares. Durante - exame clínico relatou ter notado um aumento de volume no fundo de sulco na região de canino superior. Afirmou ter notado essa alteração a pelo menos um ano e que vinha apresentando gradualmente um discreto aumento de volume.

No local da lesão a mucosa não apresentava ulceraçōes ou qualquer solução de continuidade, estando apenas com uma discreta coloração violácea e aumento de volume somente por vestibular (fig. 1).

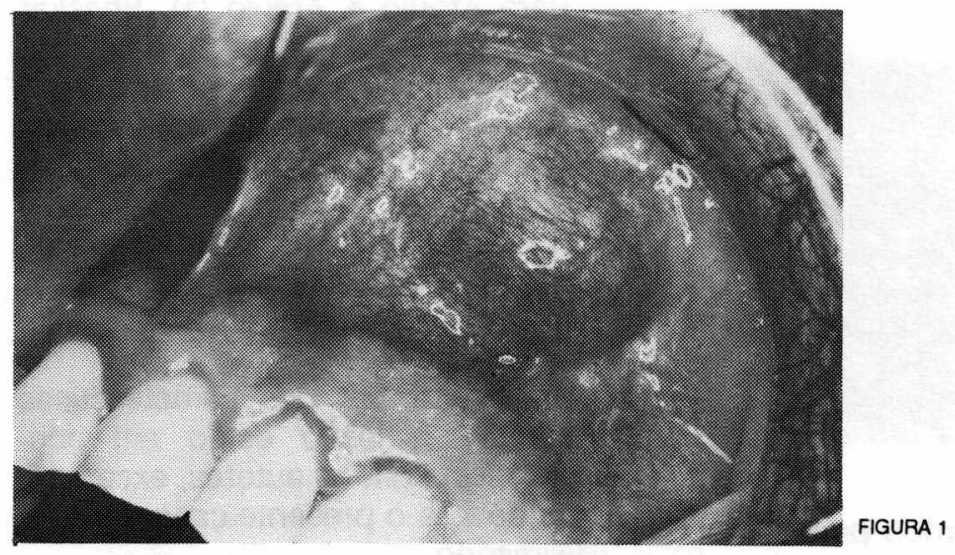

Todos os dentes adjacentes encontravam-se sem lesão e com vitalidade pulpar. Não havia alteração de imagem radiográfica no exame pe- riapical realizado. $\bigcirc$ paciente não apresentava assimetria facial nem queixa de dor na região.

À palpação notava-se lesão bem delimitada de consistência fibrosa, podendo ser levemente deslocada em qualquer sentido. Através de palpação externa percebia-se aumento de volume extra-bucal.

O paciente foi encaminhado para a disciplina de Exodontia II onde foi realizado punçăo e tentativa de aspiração do interior da lesão mas não houve nenhum tipo de material recoIhido.

Pelas características clínicas e localização da lesão optou-se pela realização de uma biópsia total que também foi realizada pela disciplina de Exodontia II.

Técnica cirúrgica: Procedeu-se uma incisão elíptica junto ao bordo inferior da lesão e o deslocamento da fibro mucosa. A lesão apresentou-se encapsulada oferecendo um

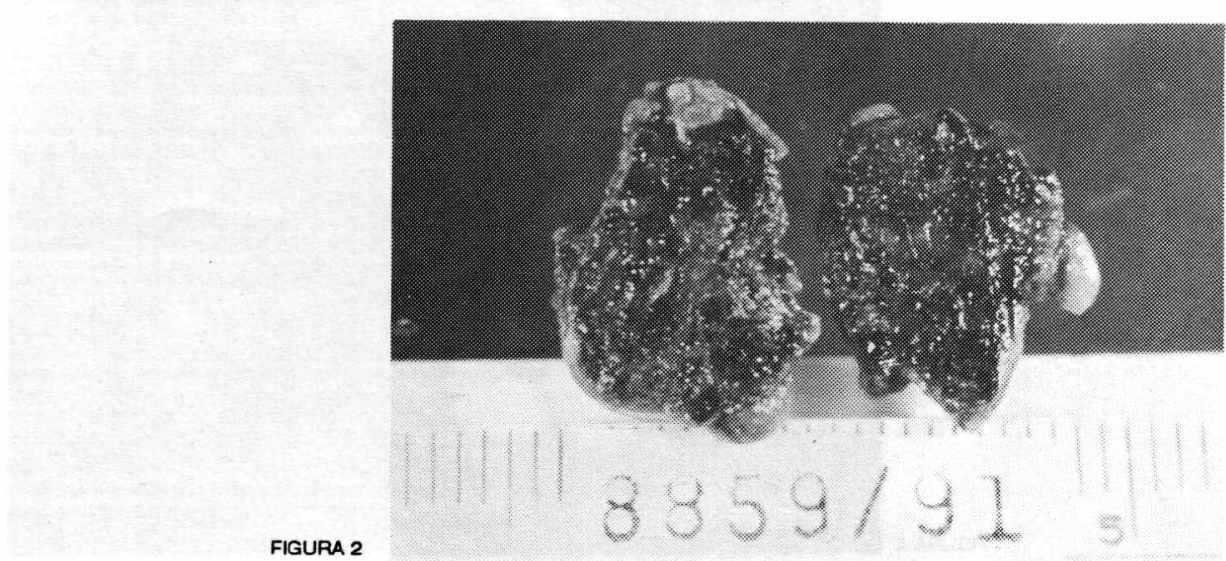

nítido plano de clivagem entre a cápsula fibrosa e os tecidos circundantes, tendo aderido a sua superfície glândulas salivares menores. Após a 
remoção total da lesão e inspeção da cavidade cirúrgica, realizou-se sutura a pontos isolados.

A peça operatória após fixada em formol $10 \%$ foi remetida ao Laboratório de Patologia da FO/UFRGS onde recebeu o número 8859/91.

Aspecto Macroscópico: Fragmento de tecido mole, de consistência fibrosa, formato nodular, coloraçăo parda, apresentando aderido a sua superfície estruturas nodulares de coloração esbranquiçada e medindo no seu maior diâmetro $15 \mathrm{~mm}$. Após a peça seccionada, revelou um interior sem cavidade ampla, também de coloração parda e consistência fibrosa. (fig. 2).

Aspecto Microscópico: Obsenouse grande proliferação de vasos formados por endotélio delgado e paredes bem dilatadas, intensa fibroplasia, ausência de infiltrado inflamatório e trombos hialinizados (fig. 3). A lesão apresentava-se bem encapsulada.

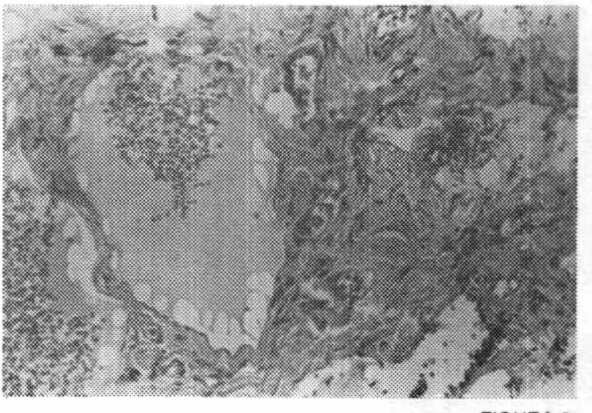

FIGURA 3

O paciente retornou para remoção de pontos e posterior controle de 90 dias (fig. 4) e recebeu alta.

\section{Discussão}

O caso apresentado contrasta com os relatos de diversos autores na medida em que encontramos as seguintes diferenças:

Segundo Bhaskar (3), Freitas (5), Thwaites (11) e Tommasi (12), hemangiomas são lesão usualmente congênitas com grande incidência em crianças onde geralmente involuem ou apresentam crescimento auto-limitante. No caso relatado o paciente tinha 28 anos e a lesão surgiu ou foi notada há aproximadamente 1 ano atrás e continuava evoluindo.

Thwaites (11) afirma que o hemangioma não apresenta cápsula, e Batsakis (2) relata que as lesōes mais profundas são menos circunscritas. Nós encontramos uma lesão perfeitamente encapsulada, permitindo a distinção de um plano de clivagem durante $o$ ato cirúrgico e que não apresentou sangramento além do normal.

Para Araújo \& Araújo (1), Bhaskar (3), Shafer (9) e Freitas (5) o hemangioma é mais comum em mulheres.

Freitas (5) considera como possível a detecção de pulsação ao fluxo sangüíneo e reabsorção do osso subjacente devido a pressão exercida pela lesão. Clínica e radiograficamente não identificamos nenhum destes aspectos.

As descriçōes das características clínicas da lesão estão em concordância com os autores, exceto no fato de que o presente caso era bem delimitado.

O aspecto microscópico da lesão relatada aqui era concordante com

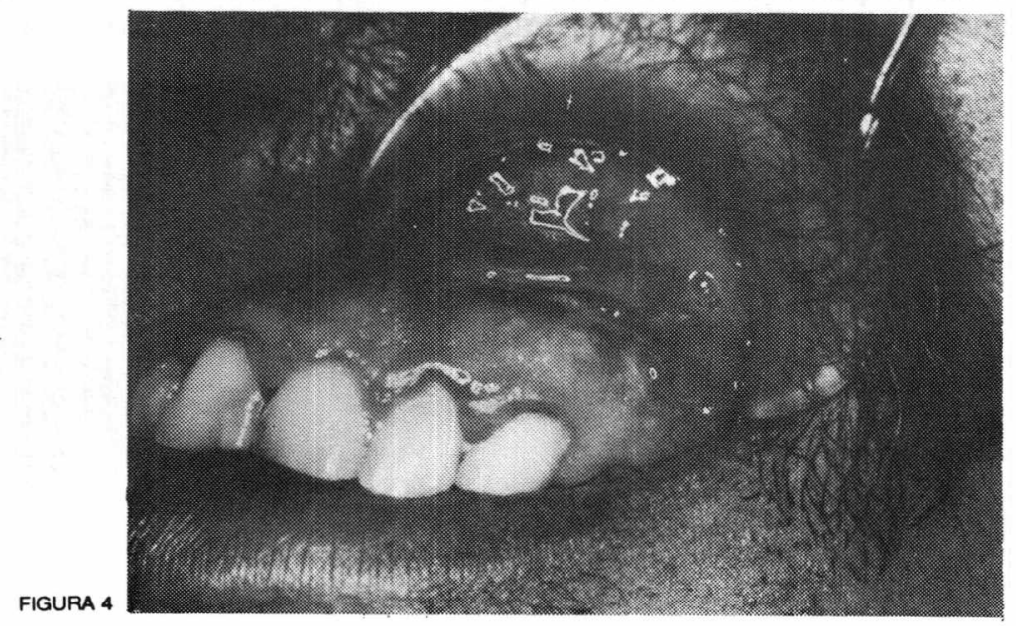

os diversos autores consultados, apresentando múltiplos capilares de diversos calibres formados por uma única camada de células endoteliais, sobre tecido conjuntivo fibroso.

De acordo com Thwaites (11) pode haver ligação do desenvolvimento $\mathrm{e}$ manutenção da lesão com o aumento do número de mastócitos na regiāo, contudo năo observamos essa relação.

\section{REFERÊNCIAS BIBLIOGRÁFICAS}

01. ARAÚJO, N.S.; ARAÚJO, V.C. Patologia bucal. Sāo Paulo: Artes Médicas, 1984. 239p. Cap. 7 Neoplasmas benignos e malignos. p.117-142.

02. BATSAKIS, J.G. Tumors of the head and neck. 2.ed. Baltimore: Willians \& Wiekins, 1982. 573p. Cap. 15. Vasoformative tumors. p.293-296.

03. BHASKAR, S.N. Patologia bucal. 4.ed. Sāo Paulo: Artes Médicas, 1989. Cap. 4. Patologia da mucosa bucal, da língua $e$ das glândulas salivares. p.446-447.

04. BIRMAN, E.; BORAKS, S.; SIMŌES, I.S.; RUNEZ, A. Hemangioma dos maxilares: revisāo da literatura $\theta$ apresentaçāo de um caso. ARS Curandi em Odontologia, Säo Paulo, v.6, n.11, p.40-46, fev. 1980.

05. FREITAS, A.; MARCUCCI, G.; RUSSO, C.A.; QUIRINO, M.R.S.; MAILART, D. Hemangioma da face - Relato de um caso clínico. Enciclopédia Bras. Odontol., Sāo Paulo, v.2., n.1., p.197-205, 1984.

06. FREITAS, A.; ROSA, J.E.; SOUZA, I.F. Radiologia odontológica. 2.ed. Sảo Paulo: Artes Médicas, 1988. 612p. Cap. 24. Aspectos radiográficos das lesōes ósseas maxilo-mandibulares. p.505-506.

07. ISHIKAWA, G.; WALDRON, C.A. Atlas colorido de patologia bucal. Säo Paulo: Santos, 1989. 193p.

08. SAPSOM, E. et al. Hematoma or hemangioma? The importance of careful differential diagnosis. GMDA BULL, p.141, jun. 1982.

09. SHAFER, W.; HINE, H.; LEVY, B. Tratado de patologia bucal. 3.ed. Rio de Janeiro: Interamericana, 1979. 837p. Cap. 2. Tumores benignos e malignos da cavidade oral. p.141-144.

10. SZANAJDER, N.; DOMINGUEZ, F.V.; CARRARO, J.; LIS, G. Hemorragic hemangioma of gingiva: report of a case. J. Periodondol., Chicago, v.44, p.576-582, sept. 1973.

11. THWAITES, M.S.; TATUM, R.C. Hemangiomas: vascular malformation of childhood, report of a case with literature rewiew. Quintessence Int., v.19, n.11, p.841-845, nov. 1988.

12. TOMMASI, A.F. Diagnóstico em patologia bucal. Sāo Paulo: Artes Médicas, 1985. 575p. Cap. 14. Tumores benignos de tecido mole. p.215-222.

13. TYLDESLEY, W.R. Oral Medicine. Oxford: University Press, 1981. 162p. Cap. 5. White patches: overgrowths and neoplasmas. p.81-106.
R. Fac. Odontol.

Porto Alegre

V. 33

N. 2

p.10-12

DEZEMBRO

1992 